\title{
Surface blistering and flaking of sintered uranium dioxide samples under high dose gas implantation and annealing
}

\author{
Guillaume Martin ${ }^{1, a}$, Gaëlle Carlot ${ }^{1}$, Pierre Desgardin ${ }^{2}$, Marylène Vayer ${ }^{3}$, \\ Claire Ramboz ${ }^{4}$, Thierry Sauvage ${ }^{2}$, Philippe Moretto ${ }^{5}$, Hicham Khodja ${ }^{6}$, \\ and Philippe Garcia ${ }^{1}$ \\ ${ }^{1}$ CEA, DEC, LLCC, 13108 Saint-Paul-Lez-Durance, France. \\ ${ }^{2} \mathrm{CNRS}$ - CEMHTI, 3A rue de la Férollerie, 45071 Orléans, France. \\ ${ }^{3}$ Faculté des sciences, CRMD, 1 rue de Chartres, 45067 Orléans, France. \\ ${ }^{4} \mathrm{CNRS}$ - ISTO, $1 \mathrm{~A}$ rue de la Férollerie, 45071 Orléans, France. \\ ${ }^{5}$ CNRS - CENBG, Chemin du Solarium, 33175 Gradignan, France. \\ ${ }^{6}$ CEA, IRAMIS, LEEL, 91191 Gif-sur-Yvette, France. \\ aguillaume.martin@cea.fr
}

Keywords: uranium dioxide, helium, hydrogen, implantation, blistering, flaking

\begin{abstract}
High helium contents will be generated within minor actinide doped uranium dioxide blankets which could be used in fourth generation reactors. In this framework, it is essential to improve our understanding of the type of damage which a pellet could incur as a result of extensive helium build-up. This paper is an attempt at tackling this issue. Sintered uranium dioxide disks have been implanted with helium ions then annealed at various temperatures. Above a concentration of 0.4 at. $\%$ and above $1000^{\circ} \mathrm{C}$, optical images of the sample surface revealed swollen grains and extensive areas which have exfoliated. Nuclear reaction microanalyses and atomic force microscopy observations were performed to demonstrate that helium has substantially precipitated within the swollen grains. Massive precipitation of the gas leads under these conditions to sample surface blistering which appears to precede flaking. Deuterium ion irradiations have also been performed at ambient and a direct flaking of the sample surface was observed, but for this phenomenon to be observed required much higher doses than in the He study, indicating that temperature could be an essential ingredient for gas to migrate and cause extensive precipitation. Such phenomena could possibly lead to degradation of the fuel.
\end{abstract}

\section{Introduction}

Separation and transmutation as a means of extensively reducing the mass and radiotoxicity of radionuclides is envisaged within the framework of a comprehensive waste management scheme. A potential material for the transmutation of minor actinides in fourth generation nuclear reactors would be a standard fuel (uranium dioxide or Mixed OXide fuel) in which minor actinides would be homogeneously dispersed. High concentrations of radioactive actinides, mostly alpha emitters, are going to generate important quantities of helium as fuel assemblies are in-reactor irradiated as well as during the poll-side storage period. In these conditions, it is essential to be able to predict whether the helium created is going to accumulate within the fuel and contribute to any extent to its swelling and degradation, or if it is going to be released, thus contributing to the pressurization of the fuel rod.

Regarding the fuel integrity, a first conservative assumption is to consider that all the gas will remain within the fuel. It is assumed in this case that high He contents are detrimental to the mechanical integrity of the fuel as a result of swelling. The threshold for the fuel to lose its mechanical integrity constitutes a first estimate of the limiting conditions which fuels may be subjected to. In minor actinide doped oxide fuels, we can expect however the gas to be partially released thus relaxing the level of internal loading induced by fuel swelling. 
A few studies related to this issue can be found in the literature. First the paper of Ronchi et al. [1] reports that a plutonium dioxide sample reduced into powder during normal handling after 40 years of storage at ambient temperature under a nitrogen atmosphere. The extreme embrittlement in this case is according to authors probably due to massive gas accumulation at the grain boundaries, which would act as low temperature trapping sites for gas atoms whereas they have been shown to constitute diffusion shortcuts at and above $800^{\circ} \mathrm{C}$ [2]. Guilbert et al. [3] studied sintered uranium dioxide samples implanted with helium ions to a maximal concentration of $\sim 1$ at. $\%$ at a depth of 2 $\mu \mathrm{m}$ below the sample surface. They observed the flaking of large areas at the sample surface after annealing at $500^{\circ} \mathrm{C}$ for 1 hour. In this article new observations of sintered uranium dioxide blistering are presented. Also, the flaking phenomena commonly associated with blistering are shown to occur in samples submitted to gas implantations and subsequently annealed.

\section{Experimental}

Sintered uranium dioxide disks depleted $\left(0.3 \%{ }^{235} \mathrm{U}\right)$ were polished then annealed for a 24 hours period at $1700^{\circ} \mathrm{C}$ in a humidified $\mathrm{Ar}-5 \mathrm{vol} . \% \mathrm{H}_{2}$ mixture (with $1.7 \mathrm{vol} . \% \mathrm{H}_{2} \mathrm{O}$ ) in order to anneal out surface defects (set A). After such a thermal treatment, the damage left over from the preparation process and in particular the polishing stage is indeed expected to be low. The presence of defects is barely detectable by positron annihilation spectroscopy [4]. However this thermal treatment reveals furrows along the grain boundaries several hundreds of $\mathrm{nm}$ deep [5]. Samples were additionally polished using a $50 \mathrm{~nm}$ silica suspension to restore the planarity of their surface (set B). The density of samples is near $98 \%$ of the theoretical density. The mean grain radius was estimated at $9 \mu \mathrm{m}$ from microscopy observations of their surface. Samples were then implanted with ${ }^{3} \mathrm{He}^{+}$ions at 500 $\mathrm{keV}$ or $1 \mathrm{MeV}$ using the Van de Graaff accelerator of the CNRS/CEMHTI in Orléans. The average implantation depth in these conditions is near 1 and $2 \mu \mathrm{m}$ respectively.

Helium depth profiles before and after sample annealing were determined by using the ${ }^{3} \mathrm{He}\left({ }^{2} \mathrm{H},{ }^{4} \mathrm{He}\right){ }^{1} \mathrm{H}$ nuclear reaction. An electronic coincidence chain detailed in [6] was set-up to filter the alpha signals received on an annular detector: more details pertaining to this nuclear reaction analysis (NRA) method are given in [6]. Helium concentration profiles have been derived from the $\alpha$-particle energy spectra using an automated method which enables the automated determination of depth profiles with optimal accuracy. The proposed procedure, extensively described in [7], relies on SIMNRA [8] simulations.

Samples were also analysed with a specific implementation of NRA using the deuteron microbeams delivered by the accelerators of the CNRS/CENBG in Gradignan and of the Pierre Süe's laboratory in Saclay. Two-dimensional images of the helium distribution at the sample surface were built up through metallic microscopy grids used for identifying the areas to be analysed. This method is further described in [2].

Some samples were isothermally annealed for one hour between $800^{\circ} \mathrm{C}$ and $1280^{\circ} \mathrm{C}$ under a reducing atmosphere $\left(\mathrm{Ar}, 10 \mathrm{vol} . \% \mathrm{H}_{2}\right)$. It is worth noting that the time to reach the maximum temperature was close to 2 hours whereas sample cooling lasted at least 3 hours. Optical and atomic force microscopy (AFM) observations were finally performed to characterise the blistering and flaking phenomena at the sample surface.

\section{Results}

Samples were implanted with helium ions at a depth of $2 \mu \mathrm{m}$ and at a fluence of $2 \times 10^{16}$ ions.cm ${ }^{-2}$. Helium was introduced at the same depth as in the samples of Guilbert et al. [3] but the implanted gas concentrations were 2.5 times lower. A depth profile of the implanted distribution is shown in Fig. 1. As expected in these conditions, the maximal concentration at the profile peak is near 0.4 at.\%. One can also notice that the helium release is relatively low in the $1080^{\circ} \mathrm{C}$ annealed samples, far below the gas release in excess of $50 \%$ measured in samples implanted at $10^{16}{ }^{3} \mathrm{He}^{+} . \mathrm{cm}^{-2}$ at a depth of $1 \mu \mathrm{m}$ which have been annealed above $1000^{\circ} \mathrm{C}$ under a secondary vacuum, with very fast heating and cooling rates [10,11]. 


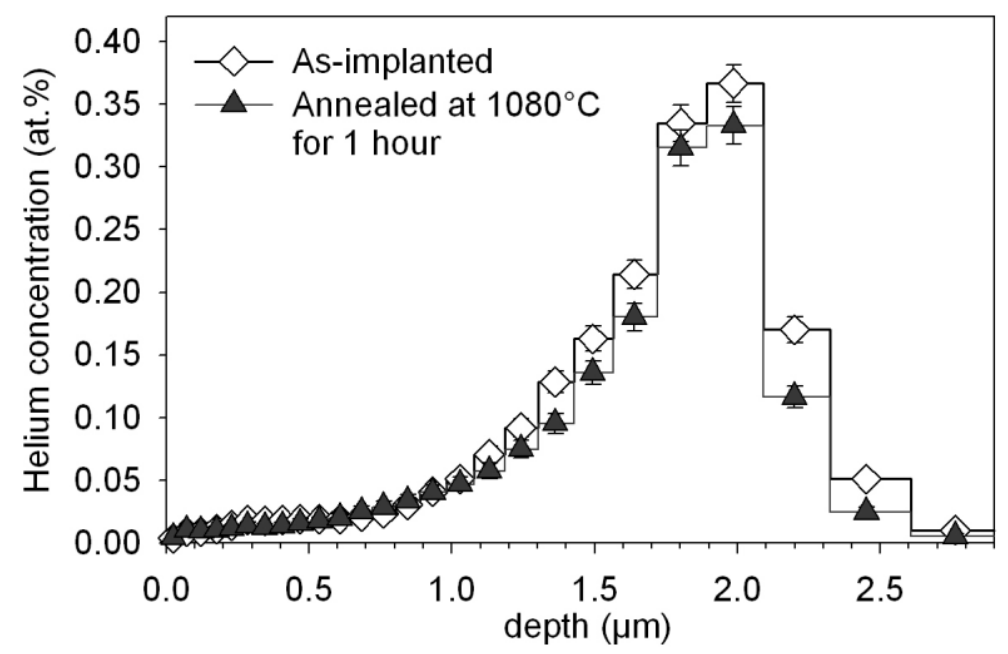

Figure 1. He depth profiles of samples implanted in ${ }^{3} \mathrm{He}^{+}$of $1 \mathrm{MeV}$ at $2 \times 10^{16}$ ions.cm ${ }^{-2}$.

After sample annealing, pink halos were revealed by optical microscopy $(\times 630)$ from $1080^{\circ} \mathrm{C}$, as shown in Fig. 2.a. Some exfoliated areas, that appear to correspond to individual grains, were also revealed: the prints of micrometre size bubbles are clearly visible inside the crater in Fig. 2.b. However, a very small fraction of the sample surface was concerned by these observations and the number of pink halos and exfoliated areas did not visibly increase with the annealing temperature.

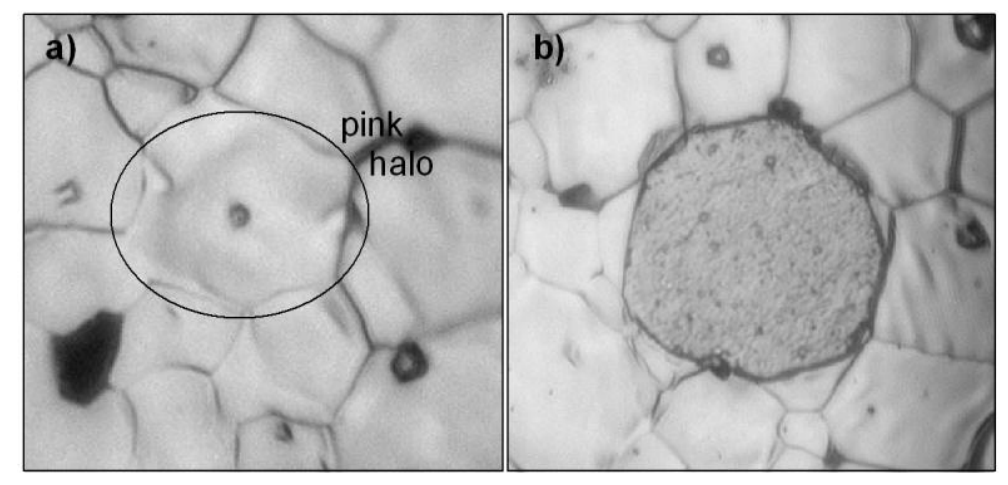

Figure 2. A halo (a) and an exfoliated area (b) observed by optical microscopy $(\times 630)$ at the surface of a sample implanted with $1 \mathrm{MeV}$ hellions at $2 \times 10^{16}{ }^{3} \mathrm{He}^{+} . \mathrm{cm}^{-2}$ then annealed at $1080^{\circ} \mathrm{C}$ for 1 hour $\left(100 \times 100 \mu \mathrm{m}^{2}\right.$ images $)$.

NRA microanalyses have shown that helium is mostly over-concentrated in grains in which the pink halos are observed. This tendency helium has to concentrate within certain grains and particularly the largest ones has already been demonstrated in these samples [2]. Such an observation is reported in Fig. 3. 

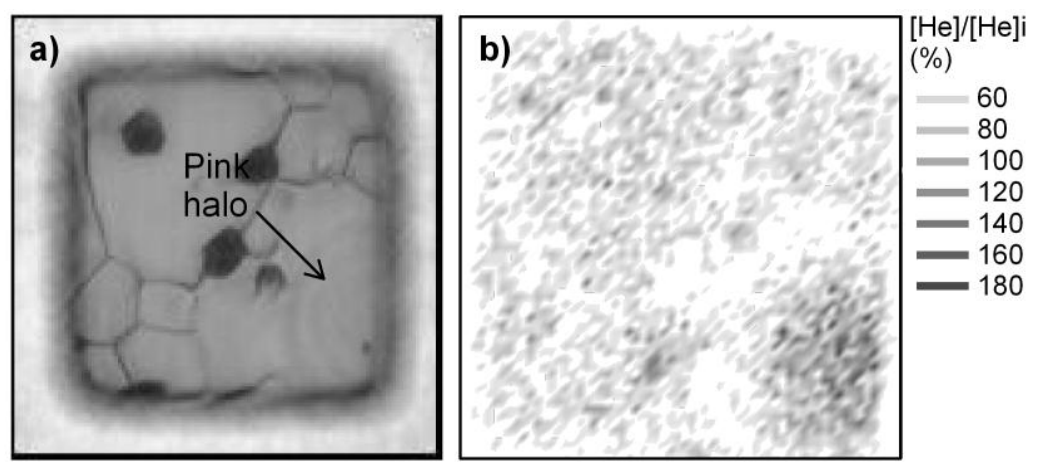

Figure 3. Optical observation $(\times 630)$ of a pink halo at the surface of a sample implanted with 1 $\mathrm{MeV}$ helium ions at $2 \times 10^{16}{ }^{3} \mathrm{He}^{+} . \mathrm{cm}^{-2}$ then annealed at $1080^{\circ} \mathrm{C}$ for 1 hour (a) corresponding $70 \times 70$ $\mu \mathrm{m}^{2}$ helium cartography (b). 3.b reveals an area of high gas concentration corresponding to where the halo is seen in the optical image.

AFM observations have finally been carried out both to confirm that the observed halos are helium blisters which induce very substantial local swelling of the fuel surface and to characterize the exfoliated areas. Typical results are presented in Fig. 4. The observed craters have a depth nearing $2 \mu \mathrm{m}$ corresponding to the depth at which the helium concentration peaks (see Fig.1).
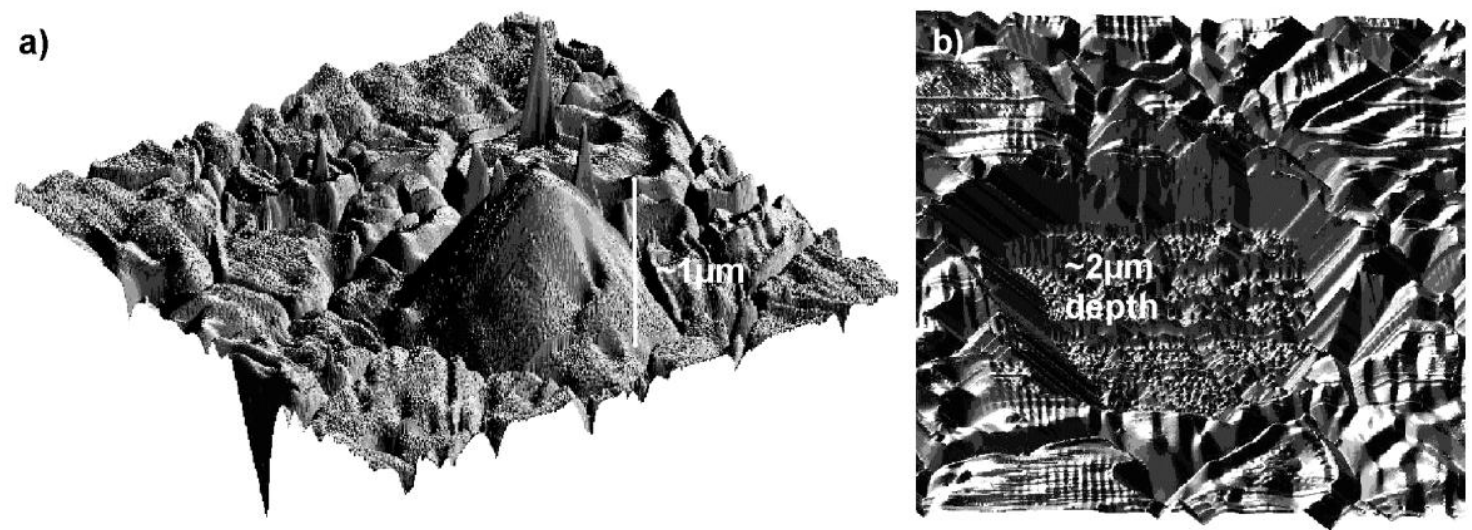

Figure $4.100 \times 100 \mu \mathrm{m}^{2}$ AFM observations of the surface of a sample implanted in $1 \mathrm{MeV}$ helium ions at $2 \times 10^{16}{ }^{3} \mathrm{He}^{+} . \mathrm{cm}^{-2}$ then annealed at $1080^{\circ} \mathrm{C}$ for 1 hour showing the effects of blistering (a) and of flaking (b).

Finally, flaking effects were also induced by the deuteron microbeam used during the analysis of samples which were implanted with ${ }^{3} \mathrm{He}$ at a depth of $\sim 1 \mu \mathrm{m}$ for a maximal ${ }^{3} \mathrm{He}$ concentration of $\sim$ 0.3 at.\% [10,11], as shown in Fig. 5. Neither flaking nor blistering effects were noticed on these samples even after annealing above $1080^{\circ} \mathrm{C}$ prior to the analysis. The analysis was performed using a $1200 \mathrm{keV}$ molecular deuteron ${ }^{2} \mathrm{H}_{2}{ }^{+}$microbeam for a current of approximately $200 \mathrm{pA}$. In these conditions, the local temperature increase under the beam spot should not exceed $150^{\circ} \mathrm{C}$ [12]. The partial flaking of analysed surfaces was observed in three different samples during the analysis, in conjunction with a sudden loss of the local helium signal. This occurred for analysis charges between 7.5 and $9 \mu \mathrm{C}$. This corresponds to an extremely high dose of deuterons of the order of magnitude of $10^{24}{ }^{2} \mathrm{H} . \mathrm{cm}^{-2}$. At this dose, the large majority of atoms should be deuterium atoms at the distribution peak, located at a depth of $4 \mu \mathrm{m}$. 


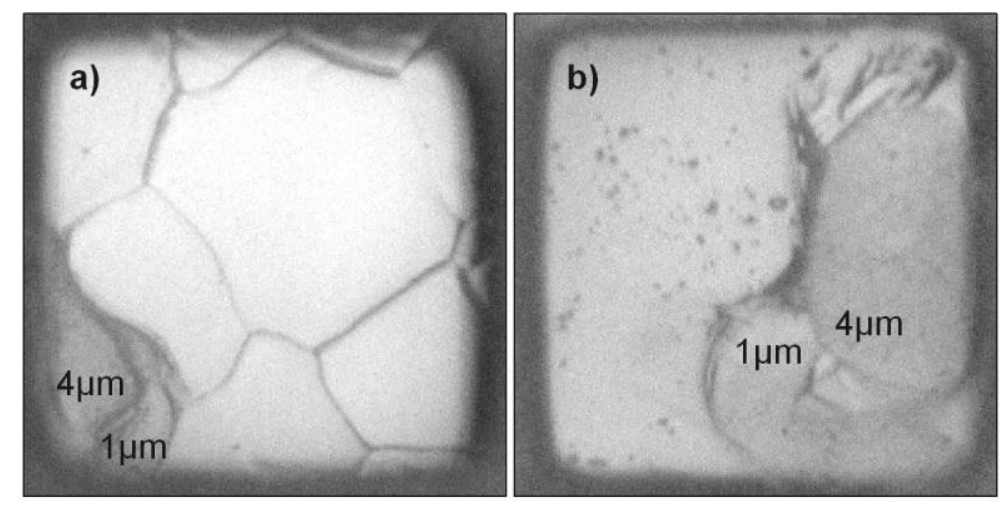

Figure 5. Optical images $(\times 630)$ of $70 \times 70 \mu \mathrm{m}^{2}$ areas of $\mathrm{UO}_{2}$ which have been microanalysed using NRA and on which a sudden flaking occurred during the analysis with a deuteron beam. Samples in (a) and (b) come respectively from sets A and B.

\section{Discussion}

The above observations suggest that helium can massively precipitate at temperatures in the region of $1080^{\circ} \mathrm{C}$ to form blisters below the sample surface. These gas blisters could sometimes induce the flaking of the sample surface.

At a maximal helium concentration of $\sim 0.4$ at.\%, a high temperature above $1080^{\circ} \mathrm{C}$ was needed to start inducing blistering and flaking effects at the fuel surface (they have ever been observed concomitantly). Guilbert et al. [3] showed however that in a sample implanted at a maximum concentration of 1 at. $\%$ and at the same depth, the surface was largely exfoliated after an annealing stage at only $500^{\circ} \mathrm{C}$. A major difference between these two studies lies in respective implanted helium concentrations. In the study of Guilbert et al., the introduced helium concentrations would be so high that short-range migration of a small fraction of the gas is enough to induce substantial blistering of the sample surface. In the present study, higher temperatures would be needed to mobilize a large fraction of the gas and to induce its massive precipitation.

It has indeed previously been shown that above $1000^{\circ} \mathrm{C}$, most of the trapped helium atoms are thermally re-soluted into the oxide matrix $[1,9]$. The gas should therefore be able to migrate above this temperature which would either induce its release or its capture by existing bubbles. In the case of annealing stages under a $\mathrm{Ar}-\mathrm{H}_{2}$ atmosphere, the long periods of several hours during which the samples remain at intermediate temperatures around $500^{\circ} \mathrm{C}$ should favour a nucleation regime during which the gas atoms and implantation defects migrate and interact to form relatively stable bubbles, explaining low gas releases as shown in Fig. 1.

Finally, in the case of helium implantations at depths of $1 \mu \mathrm{m}$ at a maximal concentration of 0.3 at.\% [10,11], blistering and flaking effects have never been observed even above $1080^{\circ} \mathrm{C}$. One can therefore deduce from these observations that a helium concentration of $\sim 0.4$ at. $\%$ is a minimal concentration above which blistering and flaking phenomena can be observed, and possibly the fuel degradation.

In addition, we can note that this concentration is far above the theoretical average gas content of approximately $4 \times 10^{-2}$ at. $\%$ present in the 40 year old plutonium oxide sample of Ronchi and Hiernaut [1], assuming that no substantial release occurred. The fact that this material reduced to powder suggests that the helium should have locally over-concentrated within the samples. This could have occurred at grain boundaries which would not constitute diffusion shortcuts at near ambient temperature as suggested by the authors. Finally, the fact that extremely high doses have to be reached to induce the flaking of the sample surface at room temperature means that the temperature should be a key ingredient for massive gas precipitation to occur.

The disintegration of the material is likely to occur from concentrations of around 0.4 at.\% only under conditions where the gas is mobile enough to form a large network of bubbles. 


\section{Summary}

$\mathrm{UO}_{2}$ sintered disks have been implanted with helium ions then annealed at various temperatures. Experimental results which consisted of helium NRA analyses coupled with optical and AFM observations indicate that the helium can precipitate to form large blisters. In this context, blistering effects seem to be precursors of sample surface flaking phenomena.

The temperature is also a key ingredient for helium to accumulate. Under conditions which enable gas migration, the disintegration of sintered uranium dioxide could begin from helium concentrations of $\sim 0.4$ at. $\%$. This value constitutes a first conservative estimate in the framework of the study of minor actinides doped oxide fuels envisaged for the transmutation of radiotoxic wastes in fourth generation reactors. However there are a number of differences between the two situations. In reactor, irradiation occurs at high temperature which is conducive to radiation damage induced stress relaxation. In addition, damage and helium is accumulated over a much longer timeframe than in an implantation experiment. Finally, damage production and helium precipitation are no doubt isotropic even down to the grain scale, whereas ion implantation may induce a directional state of stress in the material conducive to exfoliation.

\section{References}

[1] C. Ronchi and J.P. Hiernaut, J. Nucl. Mater. Vol. 325 (2004), p. 1

[2] G. Martin, P. Desgardin, T. Sauvage, P. Garcia, G. Carlot, H. Khodja, M.F. Barthe, Nucl. Instr. and Meth. B Vol. 249 (2006), p. 509

[3] S. Guilbert, T. Sauvage, H. Erramli, M.F. Barthe, P. Desgardin, G. Blondiaux, C. Corbel, J.P. Piron, J. Nucl. Mater. Vol. 321 (2003), p. 121

[4] H. Labrim, M.F. Barthe, P. Desgardin, T. Sauvage, G. Blondiaux, C. Corbel, J.P. Piron, Appl. Surf. Sci. Vol. 252 (2006), p. 3256

[5] T. Sauvage, H. Erramli, S. Guilbert, L. Vincent, M.F. Barthe, P. Desgardin, G. Blondiaux, C. Corbel, J.P. Piron, F. Labohm, J. Van Veen, J. Nucl. Mater. Vol. 327 (2004), p. 159

[6] G. Martin, T. Sauvage, P. Desgardin, P. Garcia, G. Carlot, M.F. Barthe, Nucl. Instr. And Meth. B Vol. 258 (2007), p. 471

[7] M. Mayer, SIMNRA User's Guide, Report IPP 9/113, Max-Planck Institut für Plasmaphysik, Garching, Germany, 1997

[8] G. Martin, C. Sabathier, G. Carlot, P. Desgardin, C. Raepsaet, T. Sauvage, H. Khodja, P. Garcia, accepted for publication in Nucl. Instr. and Meth. B (2012)

[9] G. Martin, P. Desgardin, P. Garcia, T. Sauvage, G. Carlot, M.F. Barthe, Mater. Res. Soc. Symp. Proc. Vol. 985 (2007), 0985-NN05-02

[10] G. Martin, Etude et simulation du comportement de l'He dans le dioxyde d'uranium, Les Editions Universitaires Européennes, Sarrebruck, Germany, 2010

[11] G. Martin, P. Garcia, C. Sabathier, G. Carlot, T. Sauvage, P. Desgardin, C. Raepsaet, H. Khodja, Nucl. Instr. and Meth. B Vol. 268 (2010), p. 2133

[12] G. Plumereau, Statistique des échauffements sous microfaisceau d'ions légers : mesures, théorie et effets physiques, Ph. D. thesis, Université Paris XI, Paris, France, 1998 